\title{
Acute kidney injury in hospitalized children: consequences and outcomes
}

\author{
Amanda M. Uber ${ }^{1} \cdot$ Scott M. Sutherland ${ }^{1}$ (1) \\ Received: 14 September 2018 / Revised: 18 October 2018 / Accepted: 19 October 2018 / Published online: 1 November 2018 \\ (C) IPNA 2018
}

\begin{abstract}
Over the past decade, the nephrology and critical care communities have adopted a consensus approach to diagnosing acute kidney injury (AKI) and, as a result, we have seen transformative changes in our understanding of pediatric AKI epidemiology. The data regarding outcomes among neonates and children who develop AKI have become far more robust and AKI has been clearly linked with an increased need for mechanical ventilation, longer inpatient stays, and higher mortality. Though AKI was historically thought to be self-limited, we now know that renal recovery is far from universal, particularly when AKI is severe; the absence of recovery from AKI also carries longitudinal prognostic implications. AKI survivors, especially those without full recovery, are at risk for chronic renal sequelae including proteinuria, hypertension, and chronic kidney disease. This review comprehensively describes AKI-related outcomes across the entire pediatric age spectrum, using the most rigorous studies to identify the independent effects of AKI events.
\end{abstract}

Keywords Acute kidney injury $\cdot$ AKI $\cdot$ Length of stay $\cdot$ Mortality $\cdot$ Renal recovery $\cdot$ Chronic kidney disease $\cdot$ Children $\cdot$ Neonates

\section{Introduction}

Acute kidney injury (AKI) describes a phenomenon marked by a rapid decline in renal function, reduced elimination of waste products, dysregulated electrolyte and acid-base balance, and impaired fluid homeostasis [1]. It has become a common complication among hospitalized children and we are fortunate that recent advances in the diagnostic approach have improved our understanding of pediatric AKI epidemiology [2-5]. Acute kidney injury is now clearly associated with poorer early outcomes and those who develop AKI frequently experience adverse consequences while hospitalized (Fig. 1) [1, 6-8]. Additionally, a connection between AKI and long-term sequelae has been established (Fig. 1); persistent renal morbidity and chronic kidney dysfunction are highly prevalent among AKI survivors [9-15]. Our epidemiologic progress has extended to neonatal AKI as well which is significant given the unique diagnostic challenges in this

Scott M. Sutherland suthersm@stanford.edu

1 Department of Pediatrics, Division of Nephrology, Stanford University, 300 Pasteur Drive, Room G-306, Stanford, CA 94304, USA population. We know that a neonate's serum creatinine at birth is a reflection of maternal renal function and, depending on gestational age, can take days or weeks to achieve true steady state. Additionally, neonates have impaired urinary concentrating ability which can mask oliguria [16-19]. However, the last few years have seen tremendous advances in our ability to accurately diagnose and study neonatal AKI. In this context, the goal of our review is to comprehensively describe AKI-related outcomes across the entire pediatric age spectrum while focusing on studies which have employed a standard, consensus AKI definition.

\section{General outcome concepts in pediatric acute kidney injury}

When reviewing AKI outcome studies, it is essential to interpret the data within the context of several general concepts. Understanding these concepts allows one to more effectively compare analyses and extrapolate findings. First, it is important to identify how AKI is diagnosed; this has a significant impact on the type of AKI events identified and the resultant outcomes. Historically, the absence of a standard AKI definition hampered our ability to understand AKI epidemiology and fully explore AKI-related 


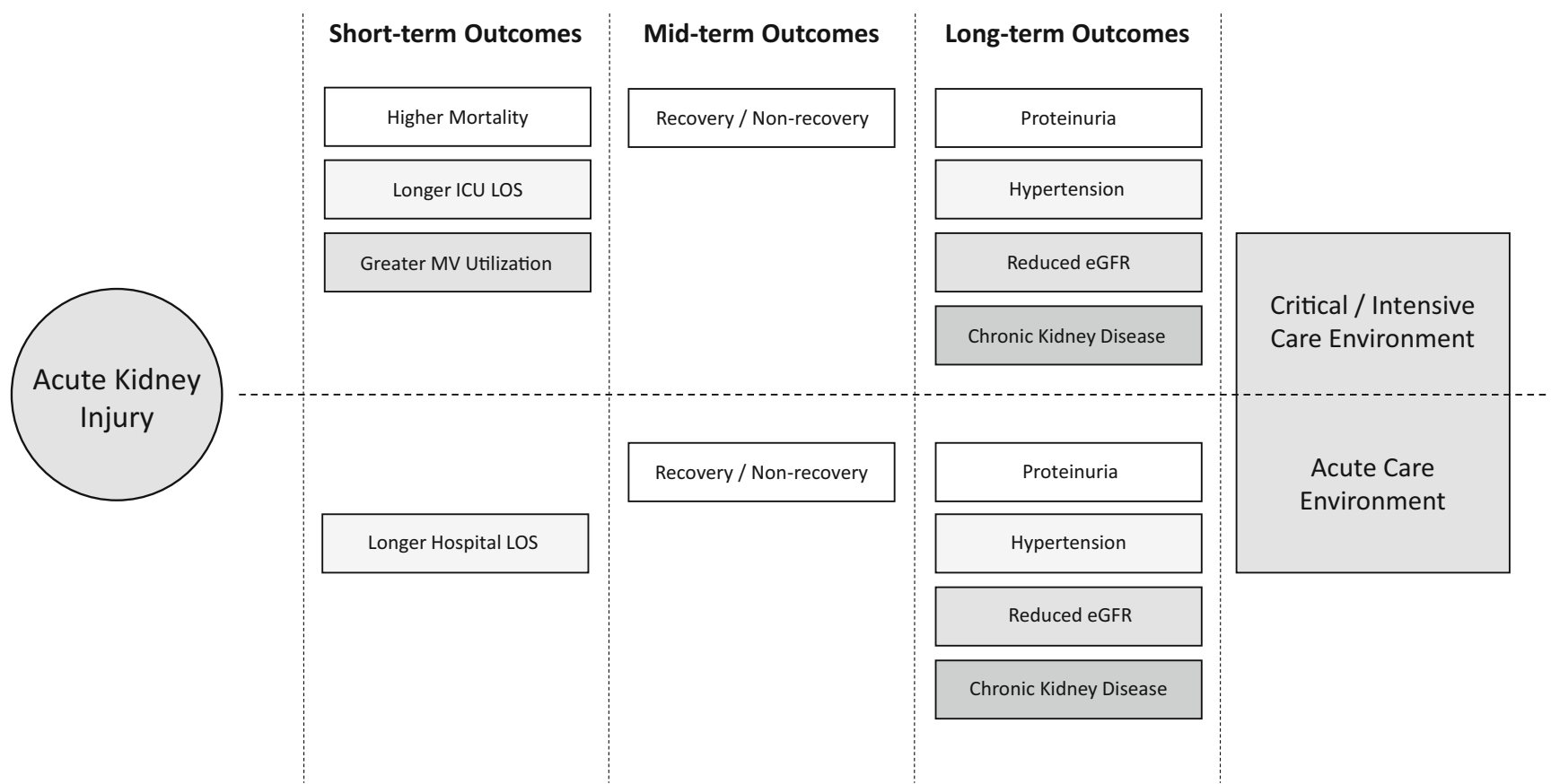

Fig. 1 Outcomes among children who develop acute kidney injury (AKI). Children who develop AKI while hospitalized are at risk for poorer short- and mid/long-term outcomes. Across both acute and critical care populations, AKI is associated with longer lengths of stay, non-recovery of baseline renal function, and chronic renal disease

outcomes. In 2004, the Acute Dialysis Quality Initiative (ADQI) group created the Risk, Injury, Failure, Loss, ESRD (RIFLE) criteria, establishing the first consensus approach to AKI identification and ushering in the modern era of AKI outcomes research [4]. Since then, however, several iterations of RIFLE have been developed and employed; these include the Acute Kidney Injury Network (AKIN), the pediatric Risk, Injury, Failure, Loss, ESRD (pRIFLE), and the Kidney Disease: Improving Global Outcomes (KDIGO) classification systems [2-5]. Although all these definitions have the same foundation, the subtle differences which exist between them can lead to significantly different epidemiologic findings. For example, pRIFLE has been described as more sensitive and AKIN as more specific, suggesting that the severity of AKI identified by the two definitions will be less and more severe, respectively [1-3, 20]. Indeed, when the two definitions were applied to the same population, the mortality risk of stage 3 AKIN defined AKI (OR 38.3, 95th CI 20.6-70.9) was significantly higher than stage 3 pRIFLE defined AKI (OR 13.6, 95th $\mathrm{CI}=7-26.3$ ) [20]. Given that KDIGO is the most current evolutionary form of the consensus approach, we hope that studies will move towards employing it preferentially as this will allow outcomes to be compared between adults and children, across diseases, and within different patient populations. Second, outcomes among children with AKI are dependent on the including proteinuria, hypertension, and chronic kidney disease (CKD). Children receiving critical care who develop AKI are more likely to require prolonged mechanical ventilation support and experienced higher mortality. eGFR estimated glomerular filtration rate, LOS length of stay

population examined. As an example, one study examined mortality rates among children with stage 3 AKI who were and were not receiving critical care; patients who developed AKI while in the intensive care unit (ICU) had an increased risk of death (likelihood ratio 14.3, 95th CI 9.2-22.4) whereas those on acute care wards did not (likelihood ratio 1.22, 95th CI 0.7-2.1) [1]. Third, AKI outcomes tend to be associated with severity of illness. For example, among neonates who experienced encephalopathy, AKI was associated with increased length of stay [21]. However, that effect was mitigated when severity of illness parameters was included in the model, and it is common for those who are most ill to have the poorest AKI-related outcomes [21, 22]. Indeed, one of the most important aspects of AKI outcomes research is determining the independent effect attributable to AKI itself.

\section{Acute kidney injury and in-hospital outcomes}

The best available data demonstrate that in hospitalized children, AKI is associated with increased need for mechanical ventilatory support, longer hospital and ICU stays, and higher mortality (Fig. 1). Despite the aforementioned relationship between disease complexity, severity of illness, and AKI, multivariate analysis continues to find that $\mathrm{AKI}$ is associated with poorer in-hospital outcomes, even after adjusting for disease 
severity and confounders. This is true not only in children and adolescents, but neonates as well; the independent effects of AKI on outcomes have been found across the entire pediatric age spectrum.

\section{Mechanical ventilation}

Across nearly all critically ill populations, AKI has been associated with an increased need for mechanical ventilation as well as longer a longer duration of support [6, 8, 23-28]. For example, the development of AKI was associated with 2.3 additional days of ventilator support $(p<0.001)$ across a general critical care population; notably, those with KDIGO stage 3 AKI received mechanical ventilation for 4.2 additional days $(p<0.001)$, suggesting a dose dependent effect [28]. Within a similar population, a single center study found that the development of AKI more than doubled the length of mechanical ventilation $(5.4$ vs. 2.2 days, $p<0.001)$ [8]. The multicenter, prospective Assessment of Worldwide AKI, Renal angina, and Epidemiology (AWARE) study, which is the largest such study performed to date, was able to demonstrate a stepwise increase in mechanical ventilation use which correlated with AKI severity (Table 1); patients with stage 1 , stage 2, and stage 3 AKI required mechanical ventilation $38.2 \%$, 40.5\%, and $50.2 \%$ of the time, respectively (vs. no AKI at 29.5\%) [6]. The same effect has been seen in neonates; Selewski and colleagues demonstrated that neonates who develop AKI after experiencing perinatal asphyxia require mechanical ventilation for 4 more days $(p<0.001)$ than those who do not develop AKI [29].

\section{Length of stay}

AKI has also been linked with longer hospital and ICU lengths of stay (LOS). In the original pRIFLE (Pediatric RIFLE or Pediatric Risk, Injury, Failure, Loss, ESRD) study, patients who experienced AKI had longer hospital
LOS (36.6 \pm 40.1 days vs. $20.5 \pm 16.6$ days, $p=0.04)$ than those without AKI [3]. This finding is highly relevant since, as previously discussed, pRIFLE is a more sensitive AKI definition which identifies milder AKI events, underscoring the strength of the association [1,20]. AWARE corroborated this finding as patients with AKI (increase of $1.33-1.51$ days, $p<0.001$ ) and severe AKI (increase of 2.77-3 days, $p<0.001$ ) had longer ICU LOS even after adjusting for severity of illness (Table 1) [6]. This association is also seen in neonates across all gestational ages. Two single center reports found that AKI increased hospital LOS among neonates by 3.4 days $(p=$ 0.02 ) and 11.7 days (95th CI 5.1-18.2), respectively [29, $30]$. The first study was performed in term infants experiencing asphyxia (mean gestational age $39 \pm$ 1.6 weeks, mean birth weight $3313 \pm 618 \mathrm{~g}$ ) [29]. The second study, which found the larger impact on LOS, examined AKI in very low birth weight (VLBW) neonates (mean gestational age $27.7 \pm 3$ weeks, mean birth weight $1016 \pm 296 \mathrm{~g}$ ) [30]. These two studies not only demonstrate the significance of AKI among newborns, they also highlight the influence that the patient population and severity of illness can have on AKI related outcomes. Importantly, the association between AKI and LOS is evident even in studies focused on non-critically ill children. For example, Zappitelli and colleagues examined 557 children receiving acute care who were administered aminoglycosides [31]. Even after adjusting for confounders, children with AKI had longer LOS. This effect was more pronounced for children who experienced more severe AKI (stage 2 and 3), which again suggests a dose-dependent effect. Rheault et al. investigated AKI in children admitted with nephrotic syndrome [32]. They too found that AKI was independently associated with prolonged hospitalization. Thus, the association between AKI and longer LOS can be found across all pediatric age groups and in both intensive and non-intensive care settings.

Table 1 Comparing Outcomes from AWARE and AWAKEN $[6,19]$

\begin{tabular}{|c|c|c|c|c|c|}
\hline & AKI definition & $n$ & Mortality & Length of stay, median (IQR) & Mechanical ventilation \\
\hline AWARE [6] & KDIGO & 4683 & $\begin{array}{l}\text { - AKI: } 6.5 \% \\
\text { - AKI: } 11 \%{ }^{*} \\
\text { - No AKI: } 2.4 \% \\
\text { - adjusted OR }: 1.8(1.2-2.7)\end{array}$ & $\begin{array}{l}- \text { No AKI: } 2 \text { days }(1-4) \\
\text { - Stage } 1 \text { AKI: } 3 \text { days }(2-7)^{*} \\
\text { - Stage } 2 \text { AKI: } 4 \text { days }(2-8)^{*} \\
\text { - Stage } 3 \text { AKI: } 5 \text { days }(2-11)^{*}\end{array}$ & $\begin{array}{l}\text { - No AKI: } 29.5 \% \\
\text { - Stage } 1 \text { AKI: } 38.2 \%{ }^{*} \\
\text { - Stage } 2 \text { AKI: } 40.5 \%{ }^{*} \\
\text { - Stage } 3 \text { AKI: } 50.2 \%{ }^{*}\end{array}$ \\
\hline AWAKEN [19] & Modified KDIGO & 2022 & $\begin{array}{l}\text { - AKI: } 10 \%^{*} \\
\text { - No AKI: } 1 \% \\
\text { - adjusted OR: } 4.6(2.5-8.3)\end{array}$ & $\begin{array}{l}\text { - No-AKI: } 19 \text { days }(9-36) \\
\text { - AKI: } 23 \text { days }(10-61)^{*}\end{array}$ & N/A \\
\hline
\end{tabular}

The in-hospital outcome results from the Assessment of Worldwide Acute Kidney Injury, Renal Angina, and Epidemiology (AWARE) and Assessment of Worldwide Acute Kidney Injury Epidemiology in Neonates (AWAKEN) studies are presented in Table 1

$* p<0.001$ vs. no-AKI

†Severe AKI vs. no severe AKI

$A K I$ acute kidney injury 


\section{Mortality}

Acute kidney injury has been linked with greater mortality in hospitalized adults in a number of studies [33-35]. For example, the AKI-EPI study, which prospectively identified AKI events in 97 ICUs across 33 countries, demonstrated that KDIGO stage 2 (adjusted OR 2.95, 95th CI 1.38-6.28, $p=$ 0.005 ) and KDIGO stage 3 (adjusted OR 6.88, 95th CI 3.88$12.23, p<0.001)$ AKI were independently associated with higher mortality [35]. Chawla et al. found that AKI events were associated with a mortality rate more than double that of myocardial infarctions [34]. In children, AKI has also been independently associated with reduced survival. In a two-center, retrospective study, Alkandari et al. found that children admitted to the intensive care unit who developed AKI were 4-8 times more likely to die than those who did not; those with severe AKI (KDIGO stage 2/3) experienced mortality rates that were 6-10 times higher, even after adjusting for severity of illness and intergroup differences. [8]. These findings were corroborated by AWARE, the aforementioned multicenter, prospective study, which found that KDIGO stage 2/3 AKI was associated with higher mortality even after adjusting for 16 covariates (Table 1) [6]. These findings have been extended to neonates by a number of analyses $[19,29,30$, 36-38]. For example, in VLBW infants, AKI was associated with a nearly two-fold increased risk of death after adjusting for confounders [38]; similar results have been found in term and near term infants [37]. Perhaps, the best illustration of the mortality impact of AKI among neonates is the Assessment of Worldwide Acute Kidney injury Epidemiology in Neonates (AWAKEN) study which evaluated the incidence of and outcomes following AKI across 2162 newborns from 24 pediatric institutions (Table 1) [19]. After adjusting for relevant confounders and intergroup differences, AKI was associated with a 4.6-fold increased risk for death (95th CI 2.5-8.3, $p<0.001$ ) [19]. It is important to note that in children, the impact of AKI on morality has been confined to critically ill patients. In one representative study, AKI was significantly associated with higher mortality in the pediatric ICU; however, this was not the case in patients receiving acute care (Fig. 2) [1]. While the best available data are not yet able to demonstrate a causative effect of AKI on survival, it certainly demonstrates that critically ill children who develop AKI experience higher mortality independent of underlying disease severity.

\section{Acute kidney injury and late outcome effects}

The data available to date demonstrate that AKI is associated with significant adverse short-term consequences. More recently, however, data regarding mid- and long-term outcomes have begun to emerge. We now know that chronic renal dysfunction is common following AKI events and proteinuria, hypertension, and chronic kidney disease (CKD) are more highly prevalent among AKI survivors than in the general population (Fig. 1). Moreover, renal recovery, or the lack thereof, seems to play an important prognostic role in children who develop AKI in the hospital.

\section{Renal recovery}

Renal recovery is a newer concept which remains inconsistently defined, and over the past 5 to 10 years, studies have used different approaches to characterize recovery [39-41]. Indeed, renal recovery has been described as a post-AKI nadir serum creatinine of less than $2 \mathrm{mg} / \mathrm{dL}$, a nadir serum creatinine that is less than $1.15 \mathrm{x}, 1.25 \mathrm{x}$, or $1.5 \mathrm{x}$ baseline, a creatinine that is within $0.3 \mathrm{mg} / \mathrm{dL}$ of baseline, no longer requiring renal replacement therapy (RRT), or no longer meeting any AKI criteria [42-48]. This has created heterogeneity among the data and complicated our interpretation; however, the data which are available clearly demonstrate the prognostic importance of this outcome concept.

Given the paucity of data regarding renal recovery in children, it is helpful to examine the relevant adult findings. One French multicenter study found that among 25,750 adults with dialysis requiring AKI, renal recovery occurred $86.2 \%$ of the time [46]. This is a relatively high rate of recovery, likely reflecting the fact that they defined recovery as no longer needing RRT. Long et al. evaluated 10,419 adults who experienced AKI while receiving either acute or critical care [48]. Overall renal recovery, when defined as a serum creatinine $<$ $1.5 \mathrm{x}$ baseline (no longer meeting stage 1 AKI criteria), was $67 \%$. Not surprisingly, the study found a dose-dependent effect and recovery was less common as AKI severity increased; renal recovery occurred in $88 \%, 58 \%$, and $44 \%$ of adults with stage 1, stage 2, and stage 3 AKI, respectively. Finally, a study of 374 adults undergoing transcatheter aortic valve replacement found that renal recovery, or a lack thereof, carries prognostic implications. Of those with AKI, 56\% experienced full renal recovery, defined as no longer meeting any stage $1 \mathrm{AKI}$ criteria at discharge [49]. While those with full recovery experienced greater 2-year mortality (adjusted HR 1.87, 95th CI 1.03-3.23) than those without AKI at all, patients with only partial recovery (discharge creatinine $>1.5 \mathrm{x}$ baseline but not requiring RRT) experienced even higher 2-year mortality (adjusted HR 2.65, 95th CI 1.4-4.7). Not surprisingly, those who continued to require RRT at discharge had the highest 2-year mortality risk of all (HR 10.95, 9rth CI 2.59-31.49).

Pediatric data, though not as extensive, are consistent with the adult findings described above. For example, Basu et al. described the post AKI course of 136 children who developed AKI and required RRT [45]. When defined as non-dialysis dependence 1 month after AKI, renal recovery occurred in $84 \%$ of patients. However, only $27 \%$ of patients had an estimated glomerular filtration rate (eGFR) $>90 \mathrm{~mL} / \mathrm{min} / 1.73 \mathrm{~m} 2$ by that 


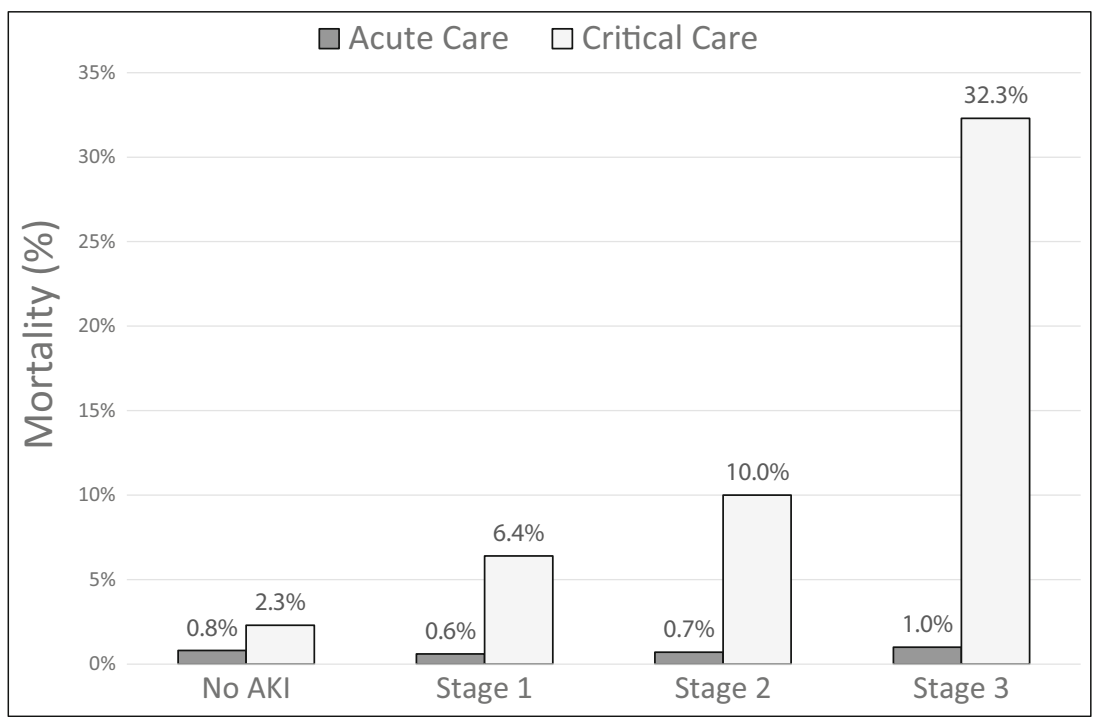

Fig. 2 Mortality in hospitalized children according to acute kidney injury (AKI) severity stage [1]. In acute care environments, mortality among children with and without AKI was similar regardless of AKI severity $(p>0.05)$. In children receiving critical care, mortality was higher among children who experienced AKI than those who did not. There was a dose- dependent effect as mortality was higher at each successive severity stage. The increases at stage 3 and stage 1 were statistically significant when compared with the prior stage $(p<0.05)$. All stages had significantly higher mortality than patients without AKI $(p<0.05)$ time, suggesting that even though many patients may not need RRT indefinitely following AKI, a far smaller proportion experience complete recovery. Hessey et al. examined 2033 pediatric ICU admissions and found that the likelihood of recovery was highly dependent on how it was defined [50]. For example, $92.5 \%$ of patients with AKI recovered function when it was defined as a discharge creatinine $<1.5 x$ baseline, but recovery only occurred in $75.9 \%$ when it was defined as discharge creatinine $<1.15 \mathrm{x}$ baseline. Hollander et al. examined 88 children who underwent cardiac transplantation and found that $62 \%$ experienced renal recovery (creatinine $<1.5 \mathrm{x}$ baseline 3 months after the AKI event) [47]. Notably, recovery was more common in the setting of mild AKI (stage 1 recovery $78 \%$ vs. stage $2 / 3$ recovery $50 \%, p<0.04$ ), echoing the dose-dependent effect of the adult findings described above. Perhaps most interestingly, this study found that non-recovery was a risk factor for the subsequent development of CKD. While none of the patients who survived AKI and recovered developed CKD, 18\% of those who did not recover from AKI developed CKD (defined as eGFR $<60 \mathrm{~mL} / \mathrm{min} / 1.73 \mathrm{~m} 2, p=0.03$ ). The concept of renal recovery is relatively new and few adult studies and fewer pediatric studies have been performed. In fact, no studies examining recovery in neonates exist at all. However, the data we do have clearly underscore the prognostic relevance of renal recovery and the importance of standardizing the definition.

\section{Chronic kidney disease}

The association between AKI and long-term renal sequelae in children has been described for over a decade. One of the earliest studies performed in hospitalized children examined
29 patients with AKI (based upon diagnostic coding) and found that proteinuria (20\%), hypertension (20\%), and an estimated GFR of less than $90 \mathrm{~mL} / \mathrm{min} / 1.73 \mathrm{~m} 2$ (13.8\%) were common following AKI [14]. Buysse and colleagues studied 19 children who developed AKI (defined as creatinine $2 \mathrm{x}$ normal value) in the setting of septic shock and found nearly identical rates of hypertension and proteinuria 10 years after the AKI event [51]. Hingorani et al. found that AKI (defined as a serum creatinine $2 \mathrm{x}$ baseline) increased the risk for $\mathrm{CKD}$ (eGFR $<60 \mathrm{~mL} / \mathrm{min} / 1.73 \mathrm{~m} 2$ ) by $70 \%$ in children undergoing stem cell transplantation [52]. Mammen et al. reviewed 126 AKI survivors (AKIN stage 1 or greater) 1-3 years after ICU discharge. They found only moderate rates of hypertension (3.2\%) and proteinuria (9.5\%); however, nearly $40 \%$ of these children had an eGFR $<90 \mathrm{~mL} / \mathrm{min} / 1.73 \mathrm{~m} 2$ [13]. Although these data are compelling, the studies are plagued by several issues which were well illustrated by a meta-analysis performed in 2014 [53]. This analysis found that the studies performed up to that point had widely variable follow-up timeframes, diagnosed AKI in different ways, defined outcomes dissimilarly, and almost universally failed to include a non-AKI comparator group.

Since then, the majority of studies have used a consensus definition for AKI, improving our ability to compare findings. Additionally, many have compared outcomes between AKI and non-AKI cohorts. As an example, one such study examined hypertension among children undergoing stem cell transplantation. They found that high blood pressure was common across the entire population; however, AKI (defined as doubling of serum creatinine, equivalent to KDIGO stage 2 or greater) was associated with a 2.5 -fold increased risk for the 
development of hypertension [54]. Menon et al. examined 100 children who developed nephrotoxic AKI and found impressively high rates of proteinuria $(68.5 \%)$, hypertension (37.6\%), and an eGFR $<90 \mathrm{~mL} / \mathrm{min} / 1.73 \mathrm{~m} 2$ (23.4\%) [15]. When compared with matched non-AKI controls, those who experienced AKI had significantly lower eGFR, more proteinuria, and a higher incidence of hypertension [15]. There have been two prospective studies performed specifically in the setting of congenital heart disease. The first is a 5-year follow-up of the Translational Research Investigating Biomarker Endpoints in AKI (TRIBE-AKI) study; the authors found that hypertension (17\%), proteinuria (8\%), and a eGFR $<90 \mathrm{~mL} /$ $\mathrm{min} / 1.73(13 \%)$ were common following cardiac surgery; however, these sequelae were not more common among the children who experienced perioperative AKI [55]. The second, entitled "Follow-up Renal Assessment of Injury Longterm after AKI (FRAIL-AKI)," compared renal findings in 51 children 7 years after undergoing cardiopulmonary bypass. The $31 \mathrm{AKI}$ and 18 non-AKI patients had similar rates of proteinuria and hypertension as well as comparable eGFRs [56]. They did note that those with AKI had higher urinary levels of IL-18 and liver-type fatty acid binding protein (LFABP) than non-AKI patients and healthy controls; this suggests that patients who experience AKI may have subtle evidence of chronic renal injury even in the absence of overt CKD. Interestingly, a subsequently published study did find that cardiac surgery-associated AKI was associated with a greater risk for CKD stage 2 or greater [57]. The 5-year cumulative incidence of CKD for patients with cardiac surgeryassociated AKI was $12 \%$, higher than the $3 \%$ seen in those without AKI (adjusted HR 3.8, 95th CI 1.4-10.4). While this study was retrospective in nature, it was large, used a consensus definition for AKI, and a rigorous definition of CKD.

The data in neonates suffer from similar issues to those described above. Namely, the studies describing the relationship between AKI and the subsequent development of CKD have been observational, small, focused on specific patient cohorts, and often use disparate diagnostic criteria for both AKI and chronic renal dysfunction [58]. However, Chaturvedi et al. examined eight observational studies and noted rates of CKD up to $20 \%$ in various populations; furthermore, proteinuria was seen in $12-66 \%$ of patients and hypertension was seen in > $10 \%$ of patients in six of the eight studies analyzed [58]. One of these studies is particularly relevant because they used a consensus definition for AKI (RIFLE), applied an appropriate definition for CKD, and included a non-AKI comparator group [59]. This analysis, performed by Zwiers and colleagues, examined 169 children who underwent extracorporeal membrane oxygenation (ECMO) during the neonatal period; they found that $\mathrm{AKI}$ was associated with increased risk for the subsequent development of CKD (OR 4.3, 95th CI 1.6-12.1, $p=0.004$ ) [59]. In summary, although we are in need of more rigorous and larger analyses, the studies performed to date clearly suggest that, across the entire pediatric age spectrum, the development of AKI puts children at risk for chronic renal disease.

\section{Summary}

Over the past decade, we have seen an increase in the quality and generalizability of AKI research primarily due to the development of a consensus AKI definition. The creation of a standard approach to AKI identification has given us a more detailed and accurate understanding of the manner in which AKI affects short- and long-term outcomes in children. The best available data now suggest that neonates, infants, children and adolescents with AKI will require mechanical ventilation for longer durations, remain in the hospital for greater periods of time, and experience higher mortality. Though some work remains to fully develop a consensus definition around renal recovery, we now know that recovery is far from universal, less likely when AKI is more severe, and has prognostic implications for long-term renal function. The studies performed to date demonstrate that proteinuria, hypertension, and reduced excretory function are highly prevalent following AKI and greatly exceed the rates seen in the general pediatric population. Additionally, there seems to be a dose-dependent association between AKI and CKD risk. Thus, children who develop AKI are at risk for long-term renal sequelae and these children warrant long-term observation and monitoring.

\section{Review Questions (answers are provided following the reference list)}

1. True or False? Studies which include a more severe phenotype of AKI are likely to find a stronger association with poor outcomes?

2. AKI is associated with higher mortality in children who are receiving
a. Intensive care
b. Acute care
c. Both intensive and acute care
d. Neither intensive or acute care

3. AKI has been associated with a greater risk for chronic renal disease in children who are receiving
a. Intensive care
b. Acute care
c. Both intensive and acute care
d. Neither intensive or acute care

4. Renal recovery is

a. A concept in need of a unifying diagnosis

b. Less common with more severe AKI 
c. Potentially associated with chronic kidney disease

d. All of the above

\section{Compliance with ethical standards}

Conflict of interest The authors declare that they have no conflicts of interest.

\section{References}

1. Sutherland SM, Byrnes JJ, Kothari M, Longhurst CA, Dutta S, Garcia P, Goldstein SL (2015) AKI in hospitalized children: comparing the pRIFLE, AKIN, and KDIGO definitions. Clin J Am Soc Nephrol 10:554-561

2. Kidney Disease (2012) Improving global outcomes (KDIGO) Acute Kidney Injury Work Group. KDIGO clinical practice guideline for acute kidney injury. Kidney Int 2:1-138

3. Akcan-Arikan A, Zappitelli M, Loftis LL, Washburn KK, Jefferson LS, Goldstein SL (2007) Modified RIFLE criteria in critically ill children with acute kidney injury. Kidney Int 71:1028-1035

4. Bellomo R, Ronco C, Kellum JA, Mehta RL, Palevsky P, Acute Dialysis Quality Initiative w (2004) Acute renal failure - definition, outcome measures, animal models, fluid therapy and information technology needs: the second international consensus conference of the Acute Dialysis Quality Initiative (ADQI) Group. Crit Care 8: R204-R212

5. Mehta RL, Kellum JA, Shah SV, Molitoris BA, Ronco C, Warnock DG, Levin A, Acute Kidney Injury Network (2007) Acute Kidney Injury Network: report of an initiative to improve outcomes in acute kidney injury. Crit Care 11:R31

6. Kaddourah A, Basu RK, Bagshaw SM, Goldstein SL, Investigators A (2017) Epidemiology of acute kidney injury in critically ill children and young adults. N Engl J Med 376:11-20

7. Sutherland SM, Ji J, Sheikhi FH, Widen E, Tian L, Alexander SR, Ling XB (2013) AKI in hospitalized children: epidemiology and clinical associations in a national cohort. Clin J Am Soc Nephrol 8: 1661-1669

8. Alkandari O, Eddington KA, Hyder A, Gauvin F, Ducruet T, Gottesman R, Phan V, Zappitelli M (2011) Acute kidney injury is an independent risk factor for pediatric intensive care unit mortality, longer length of stay and prolonged mechanical ventilation in critically ill children: a two-center retrospective cohort study. Crit Care 15:R146

9. Chawla LS, Eggers PW, Star RA, Kimmel PL (2014) Acute kidney injury and chronic kidney disease as interconnected syndromes. N Engl J Med 371:58-66

10. Chawla LS, Amdur RL, Amodeo S, Kimmel PL, Palant CE (2011) The severity of acute kidney injury predicts progression to chronic kidney disease. Kidney Int 79:1361-1369

11. Coca SG, Singanamala S, Parikh CR (2012) Chronic kidney disease after acute kidney injury: a systematic review and meta-analysis. Kidney Int 81:442-448

12. Hsu CY, Hsu RK, Yang J, Ordonez JD, Zheng S, Go AS (2016) Elevated BP after AKI. J Am Soc Nephrol 27:914-923

13. Mammen C, Al Abbas A, Skippen P, Nadel H, Levine D, Collet JP, Matsell DG (2012) Long-term risk of CKD in children surviving episodes of acute kidney injury in the intensive care unit: a prospective cohort study. Am J Kidney Dis 59:523-530

14. Askenazi DJ, Feig DI, Graham NM, Hui-Stickle S, Goldstein SL (2006) 3-5 year longitudinal follow-up of pediatric patients after acute renal failure. Kidney Int 69:184-189
15. Menon S, Kirkendall ES, Nguyen H, Goldstein SL (2014) Acute kidney injury associated with high nephrotoxic medication exposure leads to chronic kidney disease after 6 months. J Pediatr 165(522-527): 522

16. Selewski DT, Charlton JR, Jetton JG, Guillet R, Mhanna MJ, Askenazi DJ, Kent AL (2015) Neonatal acute kidney injury. Pediatrics 136:e463-e473

17. Jetton JG, Askenazi DJ (2012) Update on acute kidney injury in the neonate. Curr Opin Pediatr 24:191-196

18. Jetton JG, Askenazi DJ (2014) Acute kidney injury in the neonate. Clin Perinatol 41:487-502

19. Jetton JG, Boohaker LJ, Sethi SK, Wazir S, Rohatgi S, Soranno DE, Chishti AS, Woroniecki R, Mammen C, Swanson JR, Sridhar S, Wong CS, Kupferman JC, Griffin RL, Askenazi DJ (2017) Incidence and outcomes of neonatal acute kidney injury (AWAKEN): a multicentre, multinational, observational cohort study. Lancet Child Adolesc Health 1:184-194

20. Lex DJ, Toth R, Cserep Z, Alexander SI, Breuer T, Sapi E, Szatmari A, Szekely E, Gal J, Szekely A (2014) A comparison of the systems for the identification of postoperative acute kidney injury in pediatric cardiac patients. Ann Thorac Surg 97:202-210

21. Kirkley MJ, Boohaker L, Griffin R, Soranno DE, Gien J, Askenazi D, Gist KM (2018) Acute kidney injury in neonatal encephalopathy: an evaluation of the AWAKEN database. Pediatr Nephrol. https://doi.org/10.1007/s00467-018-4068-2

22. Sutherland SM, Kwiatkowski DM (2017) Acute kidney injury in children. Adv Chronic Kidney Dis 24:380-387

23. Li S, Krawczeski CD, Zappitelli M, Devarajan P, ThiessenPhilbrook H, Coca SG, Kim RW, Parikh CR, Consortium T-A (2011) Incidence, risk factors, and outcomes of acute kidney injury after pediatric cardiac surgery: a prospective multicenter study. Crit Care Med 39:1493-1499

24. MacDonald C, Norris C, Alton GY, Urschel S, Joffe AR, Morgan CJ, Western Canadian Complex Pediatric Therapies Follow-Up G (2016) Acute kidney injury after heart transplant in young children: risk factors and outcomes. Pediatr Nephrol 31:671-678

25. Sutherland SM, Zappitelli M, Alexander SR, Chua AN, Brophy PD, Bunchman TE, Hackbarth R, Somers MJ, Baum M, Symons JM, Flores FX, Benfield M, Askenazi D, Chand D, Fortenberry JD, Mahan JD, McBryde K, Blowey D, Goldstein SL (2010) Fluid overload and mortality in children receiving continuous renal replacement therapy: the prospective pediatric continuous renal replacement therapy registry. Am J Kidney Dis 55:316-325

26. Blinder JJ, Goldstein SL, Lee VV, Baycroft A, Fraser CD, Nelson D, Jefferies JL (2012) Congenital heart surgery in infants: effects of acute kidney injury on outcomes. J Thorac Cardiovasc Surg 143:368-374

27. Fitzgerald JC, Basu RK, Akcan-Arikan A, Izquierdo LM, Pineres Olave BE, Hassinger AB, Szczepanska M, Deep A, Williams D, Sapru A, Roy JA, Nadkarni VM, Thomas NJ, Weiss SL, Furth S, Sepsis Prevalence O, Therapies Study I, Pediatric Acute Lung I, Sepsis Investigators N (2016) Acute kidney injury in pediatric severe sepsis: an independent risk factor for death and new disability. Crit Care Med 44:2241-2250

28. Selewski DT, Cornell TT, Heung M, Troost JP, Ehrmann BJ, Lombel RM, Blatt NB, Luckritz K, Hieber S, Gajarski R, Kershaw DB, Shanley TP, Gipson DS (2014) Validation of the KDIGO acute kidney injury criteria in a pediatric critical care population. Intensive Care Med 40:1481-1488

29. Selewski DT, Jordan BK, Askenazi DJ, Dechert RE, Sarkar S (2013) Acute kidney injury in asphyxiated newborns treated with therapeutic hypothermia. J Pediatr 162(725-729):e721

30. Carmody JB, Swanson JR, Rhone ET, Charlton JR (2014) Recognition and reporting of AKI in very low birth weight infants. Clin J Am Soc Nephrol 9:2036-2043

31. Zappitelli M, Moffett BS, Hyder A, Goldstein SL (2011) Acute kidney injury in non-critically ill children treated with 
aminoglycoside antibiotics in a tertiary healthcare centre: a retrospective cohort study. Nephrol Dial Transplant 26:144-150

32. Rheault MN, Zhang L, Selewski DT, Kallash M, Tran CL, Seamon M, Katsoufis C, Ashoor I, Hernandez J, Supe-Markovina K, D'Alessandri-Silva C, DeJesus-Gonzalez N, Vasylyeva TL, Formeck C, Woll C, Gbadegesin R, Geier P, Devarajan P, Carpenter SL, Kerlin BA, Smoyer WE, Midwest Pediatric Nephrology C (2015) AKI in children hospitalized with nephrotic syndrome. Clin J Am Soc Nephrol 10:2110-2118

33. Bastin AJ, Ostermann M, Slack AJ, Diller GP, Finney SJ, Evans TW (2013) Acute kidney injury after cardiac surgery according to risk/injury/failure/loss/end-stage, acute kidney injury network, and kidney disease: improving global outcomes classifications. J Crit Care 28:389-396

34. Chawla LS, Amdur RL, Shaw AD, Faselis C, Palant CE, Kimmel PL (2014) Association between AKI and long-term renal and cardiovascular outcomes in United States veterans. Clin J Am Soc Nephrol 9:448-456

35. Hoste EA, Bagshaw SM, Bellomo R, Cely CM, Colman R, Cruz DN, Edipidis K, Forni LG, Gomersall CD, Govil D, Honore PM, Joannes-Boyau O, Joannidis M, Korhonen AM, Lavrentieva A, Mehta RL, Palevsky P, Roessler E, Ronco C, Uchino S, Vazquez JA, Vidal Andrade E, Webb S, Kellum JA (2015) Epidemiology of acute kidney injury in critically ill patients: the multinational AKIEPI study. Intensive Care Med 41:1411-1423

36. Koralkar R, Ambalavanan N, Levitan EB, McGwin G, Goldstein S, Askenazi D (2011) Acute kidney injury reduces survival in very low birth weight infants. Pediatr Res 69:354-358

37. Askenazi DJ, Koralkar R, Hundley HE, Montesanti A, Patil N, Ambalavanan N (2013) Fluid overload and mortality are associated with acute kidney injury in sick near-term/term neonate. Pediatr Nephrol 28:661-666

38. Askenazi DJ, Griffin R, McGwin G, Carlo W, Ambalavanan N (2009) Acute kidney injury is independently associated with mortality in very low birthweight infants: a matched case-control analysis. Pediatr Nephrol 24:991-997

39. Chawla LS, Bellomo R, Bihorac A, Goldstein SL, Siew ED, Bagshaw SM, Bittleman D, Cruz D, Endre Z, Fitzgerald RL, Forni L, Kane-Gill SL, Hoste E, Koyner J, Liu KD, Macedo E, Mehta R, Murray P, Nadim M, Ostermann M, Palevsky PM, Pannu N, Rosner M, Wald R, Zarbock A, Ronco C, Kellum JA (2017) Acute kidney disease and renal recovery: consensus report of the acute disease quality initiative (ADQI) 16 workgroup. Nat Rev Nephrol 13:241-257

40. Goldstein SL (2014) Renal recovery at different ages. Nephron Clin Pract 127:21-24

41. Goldstein SL, Chawla L, Ronco C, Kellum JA (2014) Renal recovery. Crit Care 18:301

42. Helgadottir S, Sigurdsson MI, Palsson R, Helgason D, Sigurdsson GH, Gudbjartsson T (2016) Renal recovery and long-term survival following acute kidney injury after coronary artery surgery: a nationwide study. Acta Anaesthesiol Scand 60:1230-1240

43. Heung M, Steffick DE, Zivin K, Gillespie BW, Banerjee T, Hsu CY, Powe NR, Pavkov ME, Williams DE, Saran R, Shahinian VB (2016) Acute kidney injury recovery pattern and subsequent risk of CKD: an analysis of veterans health administration data. Am J Kidney Dis 67:742-752

44. Laskey HL, Schomaker N, Hung KW, Asrani SK, Jennings L, Nydam TL, Gralla J, Wiseman A, Rosen HR, Biggins SW (2016) Predicting renal recovery after liver transplant with severe pretransplant subacute kidney injury: the impact of warm ischemia time. Liver Transpl 22:1085-1091

45. Basu B, Mahapatra TK, Roy B, Schaefer F (2016) Efficacy and outcomes of continuous peritoneal dialysis versus daily intermittent hemodialysis in pediatric acute kidney injury. Pediatr Nephrol 31:1681-1689
46. Bonnassieux M, Duclos A, Schneider AG, Schmidt A, Benard S, Cancalon C, Joannes-Boyau O, Ichai C, Constantin JM, Lefrant JY, Kellum JA, Rimmele T, AzuRea G (2017) Renal replacement therapy modality in the ICU and renal recovery at hospital discharge. Crit Care Med 46:e-102-ee110

47. Hollander SA, Montez-Rath ME, Axelrod DM, Krawczeski CD, May LJ, Maeda K, Rosenthal DN, Sutherland SM (2016) Recovery from acute kidney injury and CKD following heart transplantation in children, adolescents, and young adults: a retrospective cohort study. Am J Kidney Dis 68:212-218

48. Long TE, Sigurdsson MI, Sigurdsson GH, Indridason OS (2016) Improved long-term survival and renal recovery after acute kidney injury in hospitalized patients: a 20 year experience. Nephrology (Carlton) 21:1027-1033

49. Thongprayoon C, Cheungpasitporn W, Srivali N, Kittanamongkolchai W, Sakhuja A, Greason KL, Kashani KB (2017) The association between renal recovery after acute kidney injury and long-term mortality after transcatheter aortic valve replacement. PLoS One 12:e0183350

50. Hessey E, Ali R, Dorais M, Morissette G, Pizzi M, Rink N, Jouvet P, Lacroix J, Phan V, Zappitelli M (2017) Renal function follow-up and renal recovery after acute kidney injury in critically ill children. Pediatr Crit Care Med 18:733-740

51. Buysse CM, Raat H, Hazelzet JA, Hulst JM, Cransberg K, Hop WC, Vermunt LC, Utens EM, Maliepaard M, Joosten KF (2008) Long-term health status in childhood survivors of meningococcal septic shock. Arch Pediatr Adolesc Med 162:1036-1041

52. Hingorani S, Guthrie KA, Schoch G, Weiss NS, McDonald GB (2007) Chronic kidney disease in long-term survivors of hematopoietic cell transplant. Bone Marrow Transplant 39:223-229

53. Greenberg JH, Coca S, Parikh CR (2014) Long-term risk of chronic kidney disease and mortality in children after acute kidney injury: a systematic review. BMC Nephrol 15:184

54. Hoffmeister PA, Hingorani SR, Storer BE, Baker KS, Sanders JE (2010) Hypertension in long-term survivors of pediatric hematopoietic cell transplantation. Biol Blood Marrow Transplant 16:515-524

55. Greenberg JH, Zappitelli M, Devarajan P, Thiessen-Philbrook HR, Krawczeski C, Li S, Garg AX, Coca S, Parikh CR, Consortium T-A (2016) Kidney outcomes 5 years after pediatric cardiac surgery: the TRIBE-AKI study. JAMA Pediatr 170:1071-1078

56. Cooper DS, Claes D, Goldstein SL, Bennett MR, Ma Q, Devarajan P, Krawczeski CD (2016) Follow-up renal assessment of injury long-term after acute kidney injury (FRAIL-AKI). Clin J Am Soc Nephrol 11:21-29

57. Madsen NL, Goldstein SL, Froslev T, Christiansen CF, Olsen M (2017) Cardiac surgery in patients with congenital heart disease is associated with acute kidney injury and the risk of chronic kidney disease. Kidney Int 92:751-756

58. Chaturvedi S, Ng KH, Mammen C (2017) The path to chronic kidney disease following acute kidney injury: a neonatal perspective. Pediatr Nephrol 32:227-241

59. Zwiers AJ, H IJ, van Rosmalen J, Gischler SJ, de Wildt SN, Tibboel D, Cransberg K (2014) CKD and hypertension during long-term followup in children and adolescents previously treated with extracorporeal membrane oxygenation. Clin J Am Soc Nephrol 9:2070-2078

Answers:

1.True; Studies which include a more severe phenotype of AKI are likely to find a stronger association with poor outcomes?

2.a; Intensive care

3. c; Both intensive and acute care

4. $d$; All of the above 